\title{
MANEJO DA PALHA DE AVEIA PRETA SOBRE AS PLANTAS DANINHAS E RENDIMENTO DE SOJA EM SEMEADURA DIRETA ${ }^{1}$
}

\author{
BLACK OAT STRAW MANAGEMENT EFFECTS ON WEEDS AND SOYBEAN \\ YIELD IN NO-TILLAGE
}

Edson Campanhola Bortoluzzi ${ }^{2}$ Flávio Luiz Foletto Eltz ${ }^{3}$

RESUMO

A aveia preta é cultivada durante o inverno numa expressiva área do Rio Grande do Sul, proporcionando uma cobertura densa, a qual exerce efeitos sobre o crescimento das plantas daninhas e no rendimento da cultura da soja. $O$ manejo da palha da aveia é bastante variável, sendo determinado mais em função da disponibilidade de equipamentos do que pelo seu efeito na palha. Objetivou-se, através deste estudo, avaliar os efeitos de diferentes manejos da palha de aveia preta (Avena strigosa Schreb.) sobre as plantas daninhas e no rendimento de grãos de soja no sistema de semeadura direta. Um experimento foi instalado em área da Universidade Federal de Santa Maria, em Santa Maria, RS, Brasil, num solo ARGISSOLO VERMELHO Distrófico arênico. $O$ delineamento experimental foi blocos ao acaso com parcelas subdivididas com cinco repetições. Nas parcelas principais, foram distribuídos os manejos de palha: $(i)$ palha picada e distribuída; (ii) palha em pé; (iii) palha rolada; (iv) palha gradeada ; (v) palha roçada; (vi) sem palha, sem invasoras e (vii) sem palha, com invasoras. Nas subparcelas, foram alocados os tratamentos com e sem controle químico em pós-emergência das plantas daninhas. Determinaram-se densidade e massa seca das plantas daninhas, umidade e rendimento de grãos de soja, e altura de inserção do primeiro legume. Os manejos da palha de aveia preta testados não afetaram a densidade de plantas de papuã e de plantas daninhas em geral emergidas até os 15 dias após a semeadura. O rendimento de grãos nos manejos palha picada e distribuída, palha em pé, palha roçada e sem palha sem invasoras não diferiram da opção de controle das plantas daninhas em pós-emergência, demonstrando que as plantas desses manejos foram mais eficientes em conviver com as plantas daninhas que as plantas dos demais. Os manejos palha rolada, palha gradeada e sem palha com invasoras proporcionaram incremento no rendimento de grãos de soja com a opção de controle das plantas daninhas em 31, 37 e 76\%, respectivamente.

\begin{abstract}
Os tipos de manejos da palha de aveia preta não afetaram a altura de inserção do primeiro legume nem a umidade dos grãos na colheita. Os manejos da palha de aveia preta não alteraram a densidade de plantas daninhas, mas a presença de palha exerceu efeitos supressivos sobre as mesmas, reduzindo a massa seca de papuã por unidade de área e do número de plantas daninhas, com exceção do manejo palha gradeada.
\end{abstract}

Palavras-chave: palhada, biomassa de invasoras, herbicidas.

\section{SUMMARY}

An expressive area is cultivated during winter with black oat (Avena strigosa Schreb.) in Rio Grande do Sul State, Brazil, which provides a dense cover, affecting weed growth in soybean fields. Management systems for oat straw are variable, depending on the farmer's available equipment and desired management effects. The objective of this study was to evaluate black oat straw management effects on weed suppression and soybean yield. The experiment was carried out during 1997/98 growing season, at the Federal University of Santa Maria, Santa Maria, RS, on a typic Hapludalf soil. A completely randomized block design was used in a split-plot distribution with five replications. The straw managements were assigned as main plots: $(i)$ combine harvested; (ii) not managed, stand-up straw; (iii) rolled with a knife-roll; (iv) disked; (v) mowed; (vi) without straw and no weed control; (vii) without straw and with weed control. The split plots consisted of with and without post-emergency herbicide control of weeds. Above ground weed dry biomass, density of weeds and soybean grain yield were measured. The black oat straw management tested had no effect on total weed density and Brachiaria plantaginea (Link) Hitchc. density until 15 days after soybean seeding. Management disked and without straw and no weed control reduced total weed biomass and B. plantaginea biomass, with the option of post-emergency herbicide control.

\footnotetext{
${ }^{1}$ Parte da dissertação de Mestrado do primeiro autor, apresentada ao Programa de Pós-graduação em Agronomia (Solos), Universidade Federal de Santa Maria, (UFSM).

${ }^{2}$ Engenheiro Agrônomo, MSc., Doutorando do Institut National Agronomique Paris-Grignon.

${ }^{3}$ Engenheiro Agrônomo, PhD., Professor Titular, Departamento de Solos, UFSM, 97105-900, Santa Maria, RS. Bolsista do CNPq. E-mail: feltz@ccr.ufsm.br. Autor para correspondência.
} 
Management combine harvested, stand-up straw, mowed and without straw and weed control were efficient in weed suppression, presenting no differences for the treatments with the option of weed control in post-emergency. Management combine harvested, stand-up straw, rolled with a knife roll, disked and mowed neither affect grain moisture at harvest nor the first legume height insertion. However, grain moisture at harvest was higher in treatment without straw and no weed control and lower in treatment without straw and weed control.

Key words: straw, weed biomass, herbicides.

\section{INTRODUÇÃO}

A cultura de aveia preta possui, no Rio Grande do Sul, expressiva área sob cultivo antecedendo a cultura da soja, tendo como finalidade a cobertura do solo e também a produção de grãos. A preferência pela utilização de aveia preta, principalmente em rotação antecedendo a soja, é pela alta cobertura do solo que proporciona, destacando-se a sua boa distribuição sobre o solo e a persistência no terreno (ALMEIDA, 1988). A adaptabilidade às condições de clima, elevada quantidade de fitomassa seca, redução na infestação de plantas daninhas (KISSMANN \& GROTH, 1997), maior conteúdo de água no solo (CAMPOS et $\boldsymbol{a l}$. , 1994) e aumento na produtividade da soja (DERPSCH et al., 1985) também são fatores importantes para a preferência.

RUEDELL (1995) recomenda efetuar o manejo químico ou mecânico da palha da aveia, antes da semeadura da cultura de verão, objetivando uma cobertura mais uniforme e eficiente no controle das plantas daninhas e um ambiente mais propício à germinação e crescimento da cultura. Em nível de propriedade rural, o manejo é bastante variável, sendo determinado mais em função da disponibilidade de equipamentos que pelo efeito proporcionado.

O rolo-faca é um equipamento específico utilizado para o manejo da cultura de cobertura, que, segundo DENARDIN \& KOCHHANN (1993), apresenta desvantagens pelo alto custo e riscos de compactação do solo, embora seu uso proporcione bom nível de cobertura do solo (BORTOLUZZI, 1999). A roçadeira e a grade niveladora são também equipamentos utilizados para o manejo da palha, mas apresentam inconvenientes como a distribuição desuniforme da palha (roçadeira) e a movimentação do solo (grade), provocando reduções na cobertura e favorecendo a emergência de plantas daninhas (BLANCO \& BLANCO, 1991). O manejo, que simplesmente deixa a cultura da aveia entrar em senescência, permite a redução de custos, além de facilitar a semeadura da cultura subsequiente por manter a palha em pé (DENARDIN \& KOCHHANN, 1993).
Deve-se considerar não somente a quantidade de palha sobre o solo, mas também o seu manejo (BRAGAGNOLO \& MIELNICZUK, 1990). A conformação e o arranjo dessa palha sobre o solo, bem como o efeito direto do implemento, afeta variáveis como cobertura de solo, regime de temperatura e a conservação da água no solo (STRECK $\boldsymbol{e t}$ al., 1994), como também afeta as comunidades de plantas daninhas favorecendo ou desfavorecendo espécies (BUHLER, 1995; PITELLI, 1985). O presente estudo baseou-se na hipótese de que o manejo da palha de aveia preta acarreta modificações na comunidade das plantas daninhas, seja na ocorrência de espécies seja no acúmulo de fitomassa das mesmas e no rendimento de grãos da cultura da soja.

\section{MATERIAL E MÉTODOS}

Um experimento a campo foi conduzido em área experimental do Departamento de Solos da Universidade Federal de Santa Maria, RS, num solo classificado, segundo EMBRAPA (1999), como sendo argissolo vermelho distrófico arênico, textura arenosa, relevo ondulado, substrato arenito. Esse local foi cultivado com soja no verão e aveia preta no inverno, em semeadura direta, por três anos consecutivos. $\mathrm{O}$ delineamento experimental utilizado foi blocos ao acaso com parcelas subdivididas com cinco repetições. As parcelas apresentaram dimensões de 10 x $4 \mathrm{~m}$ e as subparcelas com dimensões de $10 \times 2 \mathrm{~m}$.

Nas parcelas principais foram distribuídos os tratamentos de manejo da palha de aveia, aos 158 dias após a semeadura (DAS) sobre uma cobertura uniforme de palha de aveia de $4.179 \mathrm{~kg} / \mathrm{ha}^{-1}$. Os tratamentos consistiram de: (i) PPD = palha picada $\mathrm{e}$ distribuída uniformemente sobre a unidade experimental, com auxílio de uma automotriz equipada com picador e espalhador de palha; (ii) $\mathrm{PP}=$ palha em pé, sem qualquer operação mecânica; (iii) $\mathrm{PR}=$ palha rolada, utilizando um trator mais rolo-faca; (iv) $\mathrm{PG}=$ palha gradeada, utilizando um trator mais grade leve destravada; (v) PRÇ = palha roçada, utilizando um trator mais roçadeira; (vi) SPSI = sem palha, sem invasoras, no qual a palha foi cortada com auxílio de uma roçadeira costal e retirada da área e as plantas daninhas presentes foram retiradas manualmente do local durante o ciclo da soja e, (vii) SPCI = sem palha, com invasoras, semelhante ao tratamento anterior, mas sem a retirada das plantas daninhas.

Nas subparcelas, aos 20 DAS da soja, dois tratamentos foram aplicados: (i) CCPD = controle de plantas daninhas com herbicidas latilofolicidas e graminicidas e, (ii) SCPD = sem controle de plantas daninhas. Os herbicidas pós-emergentes 
lactofen e clethodin foram aplicados nas doses recomendadas para as espécies e no estádio de duas a quatro folhas. A aspersão dos produtos foi efetuada separadamente, em pós-emergência e em condições climáticas ideais para a prática, com auxílio de um equipamento costal com vazão de calda de, aproximadamente, $125 \ell / \mathrm{ha}^{-1}$.

No dia 14 de dezembro de 1997 , semeouse a soja (cultivar FT-Abyara) e realizou-se a aplicação de $250 \mathrm{~kg} / \mathrm{ha}^{-1}$ de fertilizante da fórmula 5-20-30 na linha de semeadura. Aos 15 DAS da soja, determinou-se a densidade das plantas daninhas, através de identificação e contagem das plantas em duas áreas de $0,5 \times 1,0 \mathrm{~m}$ em cada parcela, e os resultados foram expressos em plantas por metro quadrado $\left(\mathrm{p} \ell / \mathrm{m}^{-2}\right)$. As precipitações acumuladas no período experimental de outubro de 1997 à abril de 1998 foram de $1.930 \mathrm{~mm}$ (dados da estação meteorológica da UFSM).

Para este estudo, analisaram-se somente as espécies de plantas daninhas que tiveram ocorrência em, no mínimo, três repetições. As espécies que preencheram esse requisito foram papuã (Brachiaria plantaginea (Link) Hitchc.), caruru (Amaranthus hybridus L. e A. deflexus L.), corriola (Ipomoea grandifolia (Dammer) O'Don), poaia branca (Richardia brasiliensis Goméz), tiririca (Cyperus rotundus L.) e aveia preta (Avena strigosa Schreb.), sendo que as primeiras cinco espécies foram citadas por FLECK \& CANDEMIL (1995) como sendo muito frequientes em lavouras de soja no Estado do RS, o que confere importância para as mesmas. Segundo os critérios de freqüência e de importância definidos neste estudo, as espécies que não se apresentaram em pelo menos três blocos do experimento foram analisadas conjuntamente como "demais espécies", tabela 1. A massa seca da parte aérea das plantas daninhas foi determinada através do corte rente ao solo das plantas daninhas provenientes de dois retângulos de $0,5 \times 1,0 \mathrm{~m}$ em cada parcela (aos 84 DAS da soja, no florescimento da maioria das espécies). Após secagem em estufa a $65^{\circ} \mathrm{C}$, os resultados foram expressos em $\mathrm{g} / \mathrm{m}^{-2}$. O rendimento de grãos de soja foi obtido através da colheita das plantas de uma área de $6,3 \mathrm{~m}^{2}$ em cada subparcela, realizada aos 138 DAS da soja. Após a determinação da umidade dos grãos, os dados foram transformados em $\mathrm{kg} / \mathrm{ha}^{-1}$ a $13 \%$ de umidade. A altura de inserção do primeiro legume foi medida após a senescência das folhas da soja, com auxílio de uma régua, efetuando-se 20 repetições por parcela.

As médias dos tratamentos foram submetidas ao teste Duncan em nível de 5\% de significância. A análise estatística foi efetuada utilizando-se um software estatístico (SOC, 1980) e, quando necessário, os dados foram transformados pela fórmula da raiz quadrada (STORCK \& LOPES, 1997).

\section{RESULTADOS E DISCUSSÃO}

A densidade de plantas daninhas de todas as espécies avaliadas (Tabela 1) foi semelhante entre os manejos com presença de palha na superfície do solo (PPD, PP, PR, PG, PRÇ), como também quando comparado com o tratamento sem palha SPCI, porém foram superiores ao manejo SPSI, com $1 \mathrm{p} \ell / \mathrm{m}^{-2}$ (Tabela 1 ). Os resultados demonstraram que a ausência de palha de aveia preta ou sua presença, independente de seu manejo, não alterou a densidade de plantas daninhas. RUEDELL (1994) verificou uma redução de 24 vezes no número de plantas daninhas pelo efeito do manejo mecânico da palha com rolagem, do que quando sem rolagem. BLANCO \& BLANCO (1991) verificaram um aumento da densidade de todas as espécies com a

Tabela 1 - Densidade de plantas daninhas ${ }^{(1)} 15$ dias após a semeadura de soja, sob diferentes manejos da palha de aveia preta. Santa Maria, RS, 1997/98.

\begin{tabular}{|c|c|c|c|c|c|c|c|c|}
\hline Manejos da palha & $\begin{array}{l}\text { Todas } \\
\text { espécies }^{(2)}\end{array}$ & Papũ̃ & Carurú & $\begin{array}{l}\text { Corri- } \\
\text { ola }\end{array}$ & Poaia branca & Aveia preta & Tiririca & $\begin{array}{c}\text { Demais }^{(3)} \\
\text { espécies }^{(3)}\end{array}$ \\
\hline Palha picada e distribuída - PPD & $167 \mathrm{a}$ & $3 a b$ & $10 \mathrm{abc}$ & $3 \mathrm{bc}$ & $38 \mathrm{a}$ & $94 a$ & $4 \mathrm{bc}$ & $15 \mathrm{ab}$ \\
\hline Palha em pé - PP & $171 \mathrm{a}$ & $5 \mathrm{ab}$ & $6 \mathrm{bcd}$ & $6 \mathrm{~b}$ & $54 \mathrm{a}$ & $82 \mathrm{ab}$ & $6 \mathrm{bc}$ & $13 \mathrm{~b}$ \\
\hline Palha rolada - PR & $215 \mathrm{a}$ & $30 a$ & 6 bcd & $1 \mathrm{c}$ & $66 a$ & $94 a$ & $2 \mathrm{bc}$ & $17 \mathrm{ab}$ \\
\hline Palha gradeada - PG & $175 \mathrm{a}$ & $33 \mathrm{a}$ & $20 \mathrm{a}$ & $8 \mathrm{~b}$ & $19 \mathrm{ab}$ & $56 \mathrm{bc}$ & $12 \mathrm{~b}$ & $28 \mathrm{ab}$ \\
\hline Palha roçada - PRÇ & $227 \mathrm{a}$ & $19 \mathrm{ab}$ & $3 \mathrm{~cd}$ & $7 \mathrm{~b}$ & $69 a$ & $106 \mathrm{a}$ & $6 \mathrm{bc}$ & $19 \mathrm{ab}$ \\
\hline Sem palha, com invasoras - SPCI & $202 \mathrm{a}$ & $10 \mathrm{ab}$ & $19 \mathrm{ab}$ & $22 \mathrm{a}$ & $53 a$ & $44 \mathrm{bc}$ & $18 \mathrm{a}$ & $34 \mathrm{a}$ \\
\hline Sem palha, sem invasoras - SPSI & $1 \mathrm{~b}$ & $0 \mathrm{~b}$ & $0 \quad \mathrm{~d}$ & $0 \mathrm{c}$ & $0 \mathrm{~b}$ & $0 \quad \mathrm{~d}$ & $0 \mathrm{c}$ & $1 \mathrm{c}$ \\
\hline Média & 165 & 14 & 9 & 7 & 43 & 68 & 7 & 18 \\
\hline C.V.\% & 9 & 78 & 53 & 42 & 57 & 19 & 46 & 42 \\
\hline
\end{tabular}

Ciência Rural, v. 31, n. 2, 2001. 
mobilização do solo. Embora a densidade total de plantas daninhas encontradas neste estudo seja considerada baixa, podendo ter amenizado o efeito dos tratamentos para essa variável, segundo PITELLI (1985), a baixa densidade de plantas daninhas pode refletir uma maior intensidade da interferência de cada planta infestante.

Analisando as espécies de plantas daninhas separadamente, verifica-se um comportamento diferenciado da densidade de plantas daninhas em relação aos manejos de palha avaliados. A densidade de plantas de papuã foi menos dependente do sistema de manejo da palha de aveia, pois os manejos de palha foram semelhantes entre si em relação à densidade de papuã. Contudo, a densidade de plantas de papuã nos manejos PR e PG, respectivamente com 30 e $33 \mathrm{p} \ell / \mathrm{m}^{-2}$, foram maiores do que o manejo SPSI, com zero $\mathrm{p} \ell / \mathrm{m}^{-2}$ (Tabela 1). Embora o papuã apresentasse uma densidade de plantas elevada nos manejos PR e PG, o alto coeficiente de variação (78\%) provavelmente reduziu as diferenças entre os manejos. A similaridade da densidade de plantas de papuã entre os manejos da palha pode ser explicada pela facilidade das sementes germinarem em solo úmido (BLANCO \& BLANCO, 1991), principalmente quando estão localizadas próximo à superfície do solo (KISSMANN \& GROTH, 1997). O excesso de precipitação pluviométrica, em decorrência do fenômeno "El Niño", favoreceu a germinação e emergência das plantas devido à manutenção da superfície do solo úmida durante todo o ciclo da cultura da soja. Segundo VIDAL et al. (1998), o aumento da densidade de papuã diminuiu exponencialmente o rendimento de grãos de soja.

Para os manejos PP e PR, a densidade de caruru foi $66 \%$ inferior ao $\mathrm{PG}$, devido à maior cobertura com palha. A densidade de caruru para o manejo PG foi semelhante aos manejos SPCI e PPD, provavelmente devido à movimentação do solo ocasionada pela grade no manejo PG, favorecendo a germinação das sementes. BLANCO \& BLANCO (1991) verificaram que a germinação de caruru foi estimulada pela movimentação do solo. Por outro lado, EGLEY \& WILLIAMS (1990) verificaram que a não movimentação do solo reduziu sensivelmente a germinação de sementes de caruru, ao final de três anos.

O manejo SPCI teve a maior densidade de plantas de corriola $\left(22 \mathrm{p} \ell / \mathrm{m}^{-2}\right)$, demonstrando que a presença de palha afetou a germinação das sementes dessa espécie. A densidade média de plantas de corriola nos manejos PPD, PP, PG e PRÇ foi semelhante, sendo três vezes menor que o manejo SPCI. O manejo PR apresentou menor densidade de plantas de corriola que os manejos PP, PG e PRÇ.
Para a densidade de plantas de poaia branca, o manejo PG foi semelhante aos demais manejos de palha, mas, também, foi o único que não diferiu do manejo SPSI, este último apresentando a menor densidade. A movimentação do solo provocada pela grade tende a diminuir a germinação de poaia branca, efeito contrário ao verificado com caruru.

Neste estudo, as condições climáticas apresentaram-se favoráveis para a germinação da aveia preta, tendo sido verificada nos manejos PPD, PP, PR e PRÇ, densidades semelhantes de plantas de aveia preta. $O$ manejo $P G$ reduziu a infestação de aveia preta, enquanto que os manejos PPD, PR e PRÇ aumentaram a presença de aveia preta na cultura da soja, o que, segundo KISSMANN \& GROTH (1997), pode prejudicar o estabelecimento da cultura da soja.

A densidade de plantas de tiririca nos manejos com presença de palha diferiram do manejo SPCI, sendo, neste último, três vezes superior à média dos demais (Tabela 1). A tiririca é uma planta de ocorrência em reboleiras, dificultando inferências precisas com relação a sua densidade. Contudo, observações a seu respeito são fundamentais, pois essa espécie apresenta-se com muita agressividade nas lavouras e é de difícil controle (KISSMANN \& GROTH, 1997). Porém, o desenvolvimento da tiririca é afetado pelo sombreamento do solo, onde, nessa condição, é retardado o desenvolvimento normal das plantas (KUVA et al., 1995).

Considerando as "demais espécies" de plantas daninhas, verificou-se que o manejo PP apresentou diferença significativa em relação aos manejos SPCI e SPSI, mas não diferiu com relação aos outros manejos da palha (Tabela 1). Verificouse, neste estudo, que a presença de palha de aveia não afetou a densidade da maioria das espécies de plantas daninhas, mas reduziu as densidades de corriola e tiririca. O manejo PRÇ reduziu a densidade de caruru e corriola, enquanto que o manejo PG reduziu as densidades de caruru e aveia.

Na tabela 2, são apresentados os resultados de massa seca total das plantas daninhas e de papuã, avaliadas aos 84 DAS. Por ocasião do controle das plantas daninhas em pós-emergência, verificou-se que o controle eliminou os efeitos do manejo da palha de aveia preta sobre a massa seca de papuã e de plantas daninhas em geral (Tabela 2). No entanto, sem o controle químico em pós-emergência, manifestaram-se os efeitos supressores do manejo da palha de aveia sobre o acúmulo de massa seca das plantas daninhas.

Como era esperado, o manejo SPCI proporcionou maior quantidade de massa seca total de 
Tabela 2 - Massa seca total de plantas daninhas e de papuã aos 84 dias após a semeadura de soja, sob diferentes manejos da palha de aveia preta, com e sem o controle das plantas daninhas em pósemergência. Santa Maria, RS, 1997/98.

\begin{tabular}{|c|c|c|c|c|}
\hline \multirow[t]{2}{*}{ Manejos da palha } & \multicolumn{2}{|c|}{ Massa seca de plantas daninhas $\left(\mathrm{g} / \mathrm{m}^{-2}\right)$} & \multicolumn{2}{|c|}{ Massa seca de papuã $\left(\mathrm{g} / \mathrm{m}^{-2}\right)$} \\
\hline & Sem controle & Com controle & Sem controle & Com controle \\
\hline Palha picada e distribuída - PPD & 95 c A & $14 \mathrm{a} A$ & $40 \mathrm{c}$ A & 1a A \\
\hline Palha em pé - PP & $65 \mathrm{c} \mathrm{A}$ & $18 \mathrm{a} A$ & $30 \mathrm{c} \mathrm{A}$ & $4 \mathrm{a} A$ \\
\hline Palha rolada - PR & 106 c A & $4 \mathrm{a} A$ & 69 bc A & 1a A \\
\hline Palha gradeada - PG & $233 \mathrm{~b} \quad \mathrm{~A}$ & $28 \mathrm{a} \quad \mathrm{B}$ & $153 \mathrm{~b} \quad \mathrm{~A}$ & 1a B \\
\hline Palha roçada - PRÇ & 92 c A & $18 \mathrm{a} A$ & 60 bc $A$ & $14 \mathrm{a} A$ \\
\hline Sem palha, com invasoras - SPCI & $364 \mathrm{a} \quad \mathrm{A}$ & $77 \mathrm{a} \quad \mathrm{B}$ & $280 \mathrm{a} \quad \mathrm{A}$ & $10 \mathrm{a} \quad \mathrm{B}$ \\
\hline Sem palha, sem invasoras - SPSI & $5 \mathrm{c} \mathrm{A}$ & 1a A & $1 \mathrm{c} \mathrm{A}$ & 0a A \\
\hline Média & 137 & 23 & 90 & 5 \\
\hline C.V.\% & \multicolumn{2}{|c|}{95} & \multicolumn{2}{|c|}{160} \\
\hline
\end{tabular}

Médias seguidas de mesma letra minúscula na coluna e maiúscula na linha não diferem estatisticamente pelo teste Duncan em nível de 5\%. Médias de quatro repetições.

plantas daninhas, seguido do manejo PG, com cerca de 2/3 da massa seca do manejo SPCI. Segundo CUNHA et al. (1997), a massa seca de plantas daninhas oferece um indicativo de sua interferência sobre as culturas, e DURIGAN et al. (1983a) verificaram correlação linear negativa entre matéria seca de plantas daninhas e o rendimento de grãos de soja.

O manejo SPSI acumulou uma quantidade insignificante de massa seca de plantas daninhas, porém não diferiu dos demais manejos da palha de aveia, exceto quando comparado ao PG, demonstrando que os demais manejos da palha de aveia possuem alta capacidade de evitar o acúmulo de massa seca das plantas daninhas (Tabela 2). O manejo PG destaca-se dos demais em termos de massa seca de plantas daninhas, porque afetou fortemente a conformação da palha sobre o solo, cortando-a e reduzindo a porcentagem de cobertura do solo através da incorporação parcial dos resíduos. Segundo BORTOLUZZI (1999), a gradagem pode reduzir a cobertura do solo em até $50 \%$ e, conseqüentemente, pode alterar o regime de temperatura do solo.

Verifica-se, na tabela 2 , que somente a massa seca de papuã contribuiu com cerca de $2 / 3$ da massa seca total das plantas daninhas. Esses dados concordam com os observados por CUNHA et al. (1997) e MARTINS (1994). A massa seca de papuã apresentou tendência similar à verificada na massa seca geral de plantas daninhas. Analisando-se as opções de controle, observa-se que houve similaridade entre os manejos no controle em pósemergência. Porém, na opção sem controle, o manejo SPCI alcançou maior massa seca de papuã, diferindo do manejo PG, que teve, aproximadamente, a metade da massa seca. Esses resultados demonstram que embora tenha havido grande desen- volvimento de plantas daninhas no PG, ainda assim foi inferior ao SPCI (Tabela 2).

Analisandose cada manejo e a opção de controle, verificou-se a capacidade supressora dos manejos da palha de aveia sobre as plantas daninhas, bem como a eficiência do controle químico em pósemergência. A massa seca de papuã e de plantas daninhas em geral, nos manejos com palha PPD, PP, PR, PRÇ e o manejo sem palha SPSI, não diferiram entre a opção de controle e não controle das plantas daninhas em pós-emergência. Esses resultados claramente indicam que as plantas daninhas conviveram durante todo o ciclo de desenvolvimento da soja sem que acumulassem massa seca suficiente para justificar o seu controle (Tabela 2).

Em geral, a presença de palha de aveia preta exerceu efeitos supressivos sobre a comunidade de plantas daninhas, isso porque a cobertura do solo por palha afetou a relação entre a cultura e as plantas daninhas, favorecendo a espécie de interesse econômico em detrimento das infestantes. O nível de resíduo vegetal (VIDAL $\boldsymbol{e t} \boldsymbol{a l}$., 1998) e a conformação da palha através do manejo da mesma (PITELLI, 1985) influenciam o nível de supressão.

$\mathrm{O}$ rendimento de grãos de soja não foi afetado pelo manejo da palha de aveia preta, quando foi utilizado controle das plantas daninhas em pósemergência (Tabela 3). Isso indica que, independente do manejo da palha adotado e da presença ou não de palha, o controle das plantas daninhas em pós-emergência nivelou o rendimento de grãos. Esses resultados foram semelhantes aos relatados por VIDAL et al. (1998). O excesso de chuvas, ocorrido durante a condução deste estudo, pode ter proporcionado menor competição entre a cultura e as plantas daninhas por água, diminuindo os efeitos do manejo da palha, principalmente quando comparados com o manejo SPSI.

$\mathrm{Na}$ ausência do controle químico, o rendimento de grãos de soja foi afetado pelo manejo da palha de aveia preta. Isso, provavelmente, está relacionado à capacidade diferenciada de suprimir o desenvolvimento das plantas daninhas e os fatores intrínsecos de cada manejo, como a movimentação 
Tabela 3 - Rendimento de grãos de soja sob diferentes manejos da palha de aveia preta, com e sem o controle das plantas daninhas em pósemergência.Santa Maria, RS, 1997/98.

\begin{tabular}{|c|c|c|c|c|}
\hline \multirow[t]{2}{*}{ Manejos da palha } & \multicolumn{2}{|c|}{ Rendimento de grãos de soja $\left(\mathbf{k g} / \mathrm{ha}^{-1}\right)$} & \multirow{2}{*}{$\frac{\text { Umidade dos grãos }}{(\%)}$} & \multirow{2}{*}{$\frac{\text { Altura de inserção do } 1^{\mathrm{a}} \text { legume }}{(\mathrm{cm})}$} \\
\hline & Sem controle & Com controle & & \\
\hline Palha picada e distribuída - PAPD & $2727 \mathrm{ab} \quad \mathrm{A}$ & 2771a A & $17,4 \mathrm{bc}$ & $19,5 \mathrm{a}$ \\
\hline Palha em pé - PAP & $2772 \mathrm{ab} \quad \mathrm{A}$ & $2773 \mathrm{a} \mathrm{A}$ & $17,4 \mathrm{bc}$ & $21,3 \mathrm{a}$ \\
\hline Palha rolada - PAR & $2268 \mathrm{ab} \quad \mathrm{B}$ & 2981a A & $17,8 \mathrm{bc}$ & $20,3 a$ \\
\hline Palha gradeada - PAG & 2072 bc B & $2843 \mathrm{a} \mathrm{A}$ & $18,4 \mathrm{~b}$ & $20,0 \mathrm{a}$ \\
\hline Palha roçada - PARÇ & 2072 bc A & $2540 \mathrm{a} \mathrm{A}$ & $17,8 \mathrm{bc}$ & $19,7 \mathrm{a}$ \\
\hline Sem palha, com invasoras - SPACI & 1335 c $\mathrm{B}$ & $2348 \mathrm{a} \mathrm{A}$ & $19,9 \mathrm{a}$ & $19,2 \mathrm{a}$ \\
\hline Sem palha, sem invasoras - SPASI & $3106 \mathrm{a} \quad \mathrm{A}$ & $3058 \mathrm{a} \mathrm{A}$ & $16,8 \mathrm{c}$ & $19,6 \mathrm{a}$ \\
\hline Média & 2336 & 2759 & 17,9 & 19,9 \\
\hline C.V.\% & 18 & 18 & 9 & 7 \\
\hline
\end{tabular}

Médias seguidas de mesma letra minúscula na coluna e maiúscula na linha não diferem estatisticamente pelo teste Duncan em nível de 5\% de probabilidade.

do solo e regime de temperatura. O manejo SPSI apresenta maior rendimento de grãos, quando comparado aos manejos PG, PRÇ e SPCI, mas não diferiu do PPD, PP e PR. Já os três últimos manejos foram superiores ao SPCI, demonstrando que houve aumento do rendimento de grãos de soja nesses manejos. Entretanto, os manejos de manejo da palha PPD, PP, PR, PG e PRÇ não diferiram entre si. É bem provável que a baixa eficiência dos manejos PG, PRÇ na supressão das plantas daninhas, seja devido a problemas de cobertura e movimentação do solo para o manejo do PG, e desuniformidade na cobertura do solo para o manejo PRÇ, visto que este retirou a palha de certas áreas, acumulando em outras.

O rendimento de grãos de soja pode expressar a interferência ocasionada pelas plantas daninhas que conviveram com a cultura, como também pode indicar o manejo da palha de aveia preta que proporciona a melhor relação de competitividade para a cultura. Na tabela 3 , observa-se que os manejos PR, PG e SPCI aumentaram o rendimento de grãos de soja com a utilização do controle das plantas daninhas em pós-emergência em 31,37 e $76 \%$, respectivamente. Esses resultados concordam com os relatados por CUNHA et al. (1997), que verificaram incremento no rendimento de grãos de soja na ordem de $70 \%$ quando do controle das plantas daninhas em pós-emergência. Já os manejos PPD, PP e PRÇ não resultaram em aumento no rendimento de grãos com a utilização de controle das plantas daninhas em pós-emergência, indicando a capacidade desses manejos em manter o solo com uma população de plantas daninhas que não interferiram no rendimento de grãos de soja.

Os manejos com palha não afetaram a umidade dos grãos de soja (Tabela 3). Porém, nos manejos sem palha o SPCI apresentou maior umida- de dos grãos de soja e o SPSI, a menor umidade. A média de umidade dos grãos de soja nos manejos com controle $(17,2 \%)$ e sem controle $(18,6 \%)$ evidencia que a maior umidade ocorreu na presença das plantas daninhas durante todo o ciclo da soja.

$\mathrm{Na}$ tabela 3, verifica-se que os manejos da palha de aveia preta e os manejos SPSI e SPCI não diferiram entre si em relação à altura de inserção do primeiro legume. Nessa avaliação, levou-se em consideração somente a influência do manejo da palha de aveia, desconsiderando-se os efeitos da subparcela sem controle das plantas daninhas em pós-emergência. A altura onde está inserido o primeiro legume está relacionada com a competição por luz, diferenças competitivas nas espécies daninhas e formação de flores na parte basal da planta de soja (DURIGAN et al., 1983b).

\section{CONCLUSÕES}

Os sistemas de manejo da palha de aveia preta, palha picada e distribuída, palha em pé, palha rolada, palha gradeada e palha roçada, com $4 \mathrm{t} / \mathrm{ha}^{-1}$, não afetam a densidade total de plantas daninhas emergidas até os 15 dias após a semeadura da soja.

A massa seca de papuã e de plantas daninhas como um todo não é afetada pelo manejo da palha de aveia preta, quando é realizado o controle das plantas daninhas em pós-emergência. Os manejos palha picada e distribuída, palha em pé, palha rolada e palha roçada apresentam efeitos supressivos no papuã e nas plantas daninhas em geral, eliminando o efeito benéfico do controle químico em pósemergência.

O rendimento de grãos de soja não é afetado pelo sistema de manejo de palha de aveia preta quando é realizado o controle químico das plantas 
daninhas em pós-emergência. Para os manejos palha picada e distribuída, palha em pé e palha roçada, não se justifica o controle de plantas daninhas em pósemergência, visto que esses manejos foram eficientes em manter a população de plantas daninhas sem que essas apresentassem uma expressiva interferência no rendimento de soja.

Os manejos da palha não influenciam a umidade dos grãos, nem a altura de inserção do primeiro legume.

A presença de plantas daninhas provoca aumento na umidade dos grãos de soja.

\section{AGRADECIMENTOS}

Os autores agradecem ao professor Sidinei José Lopes pela colaboração na análise estatística e ao bolsista Antônio Mostardeiro de Paula pela ajuda na condução do experimento.

\section{REFERÊNCIAS BIBLIOGRÁFICAS}

ALMEIDA, F.S. A alelopatia e as plantas. IAPAR : Londrina, 1988. 60p. (Circular $\mathrm{n}^{\circ} 53$ ).

BLANCO, H.G., BLANCO, F.M.G. Efeito do manejo do solo na emergência de plantas daninhas anuais. Pesquisa Agropecuária Brasileira, Brasília, v.26, n.2, p.215-220, fev. 1991

BORTOLUZZI, E.C. Efeito do manejo da palhada de aveia preta sobre a cultura da soja e as plantas daninhas. Santa Maria, RS, 1999. 92p. Dissertação (Mestrado em Agronomia) - Programa de Pós-graduação em Agronomia, Universidade Federal de Santa Maria, 1999.

BUHLER, D.D. Influence of tillage sistems on weed population dynamics and management in corn and soybean in the central USA. Crop Sci., Madison, v.35, p.1247-1258, 1995.

BRAGAGNOLO, N., MIELNICZUK, J. Cobertura do solo por palha de trigo e seu relacionamento com a temperatura umidade do solo. Revista Brasileira de Ciência do Solo, Campinas, v.14, p.369-374, 1990.

CAMPOS, B.H. de, REINERT, D.J., ALBUQUERQUE, J.A., $\boldsymbol{e}$ al. Avaliação temporal da umidade do solo como consequiência do tipo e percentagem de cobertura vegetal. Ciência Rural, Santa Maria, v.24, n.3, p.459-463, 1994.

CUNHA, M.M. da, FLECK, N.G., VARGAS, L. Interferência de papuã (Brachiaria plantaginea (Linck) Hitchc.) e de espécies daninhas dicotiledôneas em soja. Pesquisa Agropecuária Gaúcha, Porto Alegre, v.3, n.2, p.125-131, 1997.

DENARDIN, J.E., KOCHHANN, R.A. Plantio Direto no Brasil. Passo Fundo : Aldeia Norte, EMBRAPA-CNPT FECOTRIGO-FUNDACEP e FUNDAÇÃO ABC, 1993. Requisitos para implantação e a manutenção do sistema plantio direto: p.19-27.

DERPSCH, R., SIDIRAS, N., HEINZMANN, F.X. Manejo do solo com coberturas verdes de inverno. Pesquisa Agropecuária Brasileira, Brasília, v.20, n.7, p.761-773, 1985.
DURIGAN, J.C., FILHO, R.V., MATUO, T., et al. Períodos de matocompetição na cultura da soja (Glycine max (L.) Merril), cultivares Santa Rosa e IAC - 2.I - Efeitos sobre os parâmetros de produção. Planta Daninha, Brasília, v.1, n.2, p.86-100, 1983a.

DURIGAN, J.C., FILHO, R.V., MATUO, T., et al. Períodos de matocompetição na cultura da soja (Glycine max (L.) Merril), cultivares Santa Rosa e IAC - 2.II - Efeitos sobre características morfológicas das plantas e constituição química dos grãos. Planta Daninha, Brasília, v.1, n.2, p.101-114, 1983b.

EGLEY G.H., WILLIAMS, R.D. Decline of weed seeds and seedling emergence over five years as affected by soil disturbances. Weed Science, Champaign, v.38, p.504-510, 1990.

EMBRAPA Centro Nacional de Pesquisa de Solos. Sistema brasileiro de classificação de solos. Brasília : EMBRAPA produção de informações; Rio de Janeiro : Embrapa Solos, 1999. 412p.

FLECK, N.G., CANDEMIL, C.R.G. Interferência de plantas daninhas na cultura da soja (Glycine $\max$ (L.) Merrill). Ciência Rural, Santa Maria, v.25, n.1, p.27-32, 1995.

KISSMANN, K.G., GROTH, D. Plantas infestantes e nocivas. 2 ed. São Paulo : BASF, 1997. Tomo I. 825p.

KUVA, M.A., ALVES, T.L.C., ERASMO, E.L.A. Efeitos da solarização do solo sobre o desenvolvimento da tiririca. Planta Daninha, Brasília, v.13, n.1, p.26-31, 1995.

MARTINS, D. Interferência de capim-marmelada na cultura da soja. Planta Daninha, Brasília, v.12, n.2, p.93-99, 1994.

PITELLI, R.A. Interferência das plantas daninhas em culturas agrícolas. Informe Agropecuário, Belo Horizonte, v.11, n.129, p.16-27, 1985.

RUEDELL, J. Plantio direto na região de Cruz Alta. Convênio FUNDACEP/BASF. 1985-1994. Cruz Alta, RS : Fundação Centro de Experimentação e Pesquisa Fecotrigo FUNDACEP, 1994. Controle de plantas daninhas: p.40-82.

RUEDELL, J. Dessecação e controle de plantas infestantes no sistema plantio direto. In: SEMINÁRIO INTERNACIONAL DO SISTEMA PLANTIO DIRETO, 1995, Passo Fundo, RS. Anais .... Passo Fundo, RS : EMBRAPA-CNPT, 1995. v.1, 182p. p.21-27.

SOC - SOFTWARE CIENTÍFICO Cálculos estatísticos. NTIA/EMBRAPA, disquete 3 1/2, Sistema operacional MSDOS, 1980.

STORCK, L., LOPES, S. J. Experimentação II. Santa Maria UFSM, CCR, Departamento de Fitotecnia, 1997. 197p.

STRECK, N.A., SCHNEIDER, F.M., BURIOL, G A. Modificações físicas causadas pelo mulching. Revista Brasileira de Agrometeorologia, Santa Maria, v.2, p.131$142,1994$.

VIDAL, R.A., THEISEN, G., FLECK, N.G., et al. Palha no sistema de semeadura direta reduz a infestação de gramíneas anuais e aumenta a produtividade da soja. Ciência Rural, Santa Maria, v.28, n.3, p.373-377, 1998. 